\title{
Assessing Food Supply Chain Sustainability Based on the Framework of Fussy TOPSIS
}

\author{
Bao'e Song ${ }^{1}$ \\ ${ }^{1}$ School of Economics and Management, Shannxi University of Science and Technology, Xi'an, China \\ Correspondence: Bao'e Song, Shannxi University of Science and Technology, Xi'an, 710021, China. E-mail: \\ songbaoestrive2008@hotmail.com
}

Received: May 7, 2020

doi:10.5539/ijbm.v15n8p132
Accepted: June 20, 2020

Online Published: July 26, 2020

URL: https://doi.org/10.5539/ijbm.v15n8p132

\begin{abstract}
Environmental degradation has been a great concern for Chinese people. Sustainable management serves a critical avenue to solve environmental problems and has become increasingly popular and important in theoretical and practical terms. Sustainability assessment is conducive to the shift and improvement of sustainability performance. The aim of this article is to propose an evaluation framework through constructing a comparatively comprehensive set of indicators so as to measure one of the most significant yet complex supply chains. The assessment methodology is the Fuzzy TOPSIS methodology which is utilized to ascertain the weights of indicators as well as comparison of different food supply chains. The study enables stakeholders to gain a better understanding of food supply chain sustainability as well as further inform their decisions. Scholars and practitioners in the sphere of sustainable research in China could utilize the findings of the article to take corresponding countermeasures to enhance sustainability of food supply chain so as to relieve the increasingly severe environmental problems.
\end{abstract}

Keywords: food supply chain, sustainability, Fuzzy TOPSIS

\section{Introduction}

Environmental challenges, such as global warming, frequent hazy weather and excessive PM 2.5 in air, etc., have aroused great societal concern in China during the past decade. Administrative bodies have been stipulating and enacting a succession of environment-related regulations and legislations. There is a pervasive desire among scholars alongside practitioners to take economic, environmental together with social dimension of businesses into consideration. In response, an increasing number of organizations have incorporated sustainable management(SM) into their operational philosophy to address public environmental concern and conform to corresponding laws. World Commission on Environment and Development (WCED) defines sustainable development as "development, which meets the needs of the present without compromising the ability of future generation to meet their own needs". Sustainability assessment is being increasingly regarded as a significant approach to facilitate the shifting process towards sustainability (Pope, Annandale and Morrison-Saunders 2004). The same authors go on to point out that sustainability evaluation is "a new and evolving concept" and literature of effective sustainability assessment conducted by scholars are few and far between.

Food-related industry is one of the most significant and critical industries for human society. Liu (2011) nevertheless underscores that food industry is an increasingly heavy environmental polluter and resource consumer. The International Resource Panel of the United Nations Environment Program (2010) also argues that agriculture and food-related consumption are two of the most significant factors of environmental problems which involve habitat diminishing, global warming, water depletion and toxic gas emissions. Thus, it is urgent and significant to examine the environmental dimension of food supply chain (FSC) rather than solely focus on economic parameters. In modern times, technology has been advancing with each passing day and improved the well-being of humankind. Likewise, the agro-food system has undergone significant modernization and mechanization (Ilbery and Maye, 2004) which are characterized by advanced food processing technologies and food additives. However, the mechanical and technological advancement in food sector didn't simultaneously bring about the promotion of food quality. Food safety issues such as food poisoning, contamination and food-borne illnesses have greatly affected the development of social economy and well-being of the consumers. The last decade has witnessed unprecedented public critical concerns surrounding food quality and safety issues. 
While such concerns culminated with San Lu poisoned milk powder scandal in China killing 6 infants and sickening at least 300,000 infants, they have been caused by a sequence of previous food safety problems dating back to carbinol adulterated alcohol and fatal chemical additive "ractopamine or clenbuterol" in pork (Wang, 2010). It is a great public concern that the impact of food supply chains on social well-being has to be re-examined and resolved properly. As Fritz and Schiefer (2008) emphasize, food sector is amongst the first to be investigated in terms of its sustainability, including pollution, labor standards and waste issues.

Nevertheless, there is not much well-established literature for the evaluation of sustainable performance of food supply chains in China. A detailed literature search with the concept related to sustainable food supply chain (SFSC) was performed through the most widely-recognized online academic resource CNKI (Chinese National Knowledge Infrastructure). CNKI is also a gateway to get access to world-renowned databases including Elsevier、Springer、Wiley, among other academic resources. Although a number of scholars have undertaken China's sustainable FSC research, their major focuses are centered on simple description of SFSC definition as well as elementary qualitative relevant analysis. Very few papers have addressed the qualitative research of China's FSC utilizing multicriteria decision making method to assess and compare FSC. The scarcity of SM research in the context of developing countries like China is also highlighted by Seuring and Gold (2013). According to the searching conclusions of the current paper, they point out that SM related research in developing countries is "vastly underrepresented". Since the concern of the public on sustainable issues is mounting, Chinese stakeholders expect further sustainability theoretical and practical literature.

Against this backdrop, it is urgent and meaningful to undertake research into the food industry sustainability issues thoroughly. The paper seeks to study the food supply chain in totality from the perspective of its economic environmental and social implications. The remaining part of the paper is constructed as follows: Section 2 provides a concise and comprehensive review of food supply chain together with a critical literature review with regard to SFSC. In Section 3, a detailed exposition of sustainable indicators and construction of assessment framework are presented, the weighting scheme is realized by the employment of AHP method. The proposed methodology is further applied to food supply chains to testify its effectiveness in Section 4. In the final part of this paper, the implication and conclusion section present the functions of the proposed sustainability framework and discuss its future related research area.

\section{Terminology and Literature Review}

\subsection{Food Supply Chain}

The food supply chain is multi-tiered, particularly complex and one of the largest industry sectors in the world. It was initiated by Denouden Zuurhie (1996) and of critical significance to the society (Barrett et al.1999). According to Environment, Food and Rural Affairs (DEFRA 2006), food supply chain encompasses the processes of agricultural production, food processing, food wholesaling, food retailing and food catering.

The literature on food supply chain is extensive and has been contributed to by numerous scholars. With the aim to conduct risk assessment, Wang et.al.(2012) proposes to employ fuzzy set theory as well as analytical hierarchy process to undertake in-depth analysis of food safety in the field of food supply chain. Diabat, Govindan and Panicker (2012) create a model which identifies and evaluates related risks of food supply chain utilizing interpretive structural modeling (ISM). In the same vein, Song (2011) introduces an approach to manage food supply chain risk by analyzing a sequential game between retailers and government. A conceptual model is advocated by Dani and Deep(2010) to mitigate FSC risk from a reactionary standpoint. From the reviewed literature above, it can be shown that the focus of research is mainly on the issue of food safety rather than in economic、environmental and social terms.

\subsection{Supply Chain Sustainability Assessment}

It is evident that the concept of sustainability serves as the basis of sustainability assessment. However, its interpretation has created heated debate and has been approached "from an inter-generational philosophical position to a multi-dimensional term for business management" (Ahi \& Searcy, 2013). Given its definition is ambiguous and vague, confusions quite often arise when the concept of sustainability is put into practice. The study on sustainability initiatives of early scholars (Zhu etc., 2011; Wu, Tseng \& Vy, 2011; Mintcheva, 2005; Lin Chen \& Nguyen, 2011; Olugu Wong \& Shaharoun, 2011;Tsai \& Hung, 2009) are prone to mainly focus on economic and environmental concerns leaving social issues somewhat aside. More recently, it is increasingly espoused that a triple bottom line (TBL) which attaches equal importance to economic, environmental and social consideration (Bekele etc., 2012; Ahi and Searcy, 2013; Yakovleva, Sarkis \& Solan, 2012) should be adopted in addressing sustainability. According to Elkington (1999), the terminology triple bottom line is defined as "simultaneous pursuit of economic prosperity, environmental quality, and social equity". 
Sustainable supply chain ( SSC) comes into being when sustainability is integrated in the field of supply chain. According to Jain et al. (2009), supply chain is a dynamic process that incorporates the continuous flow of materials, funds and information across multiple functional areas among supply chain players. Likewise, sustainable supply chain is understood as the process of material, capital as well as information flows when economic, environmental as well as social goals are taken into consideration from the perspective of stakeholder requirements. Just as Ahi and Searcy (2013) highlight, sustainable supply chain is "the voluntary integration of economic, environmental and social considerations with key inter-organizational business systems aimed at the realization of efficient as well as effective management of material, information, and capital flows so as to satisfy stakeholder requirements".

There are a wide variety of literature centered on sustainability, SSC as well as sustainability assessment. Seuring and Gold (2013) systematically review the literature on sustainability management and further underscore the conceptual, theoretical and empirical dimensions of sustainability. Through extensive literature review related to green and sustainable supply chain, Ahi and Searcy (2013) propose a new definition of SSCM. In their research, Walker and Touboulic (2015) investigate theoretical perspectives in sustainable supply chain management, conduct a comprehensive literature review with the focus of SSCM as well as summarize relevant theories. Likewise, Govindan (2018) also conduct a comprehensive literature review on SSCM and SSC in the food industry, identify different theories that are related to sustainable consumption and production and finally develop a conceptual framework by identifying the indicators, drivers, and barriers from the perspective of stakeholder theory.

Sustainability assessment is being increasingly regarded as a crucial research topic to facilitate the shift towards sustainability. Pope etc.(2004) endeavor to clarify the concept of sustainability assessment in order to determine whether or not an initiative is sustainable". He, Luo and Huang (2019) utilize a graph theory-based approach and propose a hierarchical evaluation system for mechanical product sustainability assessment with indicators in terms of energy, environment, resource, technology, and economy. Demeke etc. (2018) utilize externality costs, full cost of production and GNVA to assess whether Bounty paper towels are sustainable. Babu and Mohan (2018) adopt an integrated framework to assessing sustainability of supply chains utilizing evolutionary game theory.

Through scholarly search on website with a structured keyword "sustainability", or "sustainable", and "food" by utilizing the "All Fields" category, there are a number of relevant literature available online from the peer-reviewed journals and only three mainly focus on sustainability assessment in the field of food industry. The attempt is made by Ilbery and Maye (2005), Bekele etc (2012), and Yakovleva etc (2012) whose research are all based in the context of developed countries like UK and Sweden. Based on the review and exploration of existent literature on food supply chain and sustainable supply chain, it is easily and clearly indicated that there is a lack of studies in terms of sustainability of food chain in general. Moreover, no attempt has been made to construct a holistic qualitative model to evaluate and benchmark Chinese food supply chain sustainability in particular. A dedication of such a framework to incorporate Fuzzy TOPSIS into methodology is not in existence. Therefore, the Fuzzy TOPSIS approach of evaluating FSCM sustainability performance will be of immense benefit to the academic and practical community.

\section{Integrated Sustainability Assessment Framework}

A methodological framework is proposed to assess the sustainability of food supply chains that incorporates the following stages:

(1) Development of sustainability indicators.

(2) Assessment model development with Fuzzy TOPSIS.

\subsection{Identification of Sustainability Indicators}

In order to effectively assess food supply chain, the development of a range of indicators in the assessment framework is of paramount importance. It is considered that food supply chain consists of agriculture (farming), food processing, food transportation, food retail and food catering stages. The indicators developed in this paper have been collected and further selected through a scan of literature (Yakovleva etc., 2012;) and is specific for food industry rather than generic. Indicators of each FSC stage are designed from economic、environmental and social dimensions. A total of indicators are developed and reported in Table 1. 
Table 1. Sustainability indicators for food supply chain

\begin{tabular}{|c|c|c|c|}
\hline $\begin{array}{l}\text { supply chain } \\
\text { stages }\end{array}$ & economic dimension & environmental dimension & social dimension \\
\hline Agriculture & Total output & Cost of water consumption & $\begin{array}{l}\text { farmers' consciousness of } \\
\text { sustainability }\end{array}$ \\
\hline \multirow{4}{*}{ food processing } & \multirow[b]{2}{*}{ Total output } & $\begin{array}{l}\text { soil quality } \\
\text { Cost of waste disposal }\end{array}$ & \\
\hline & & Cost of energy consumption & $\begin{array}{l}\text { mission statement on } \\
\text { sustainability }\end{array}$ \\
\hline & \multirow[t]{2}{*}{ labor productivity } & Cost of water consumption & $\begin{array}{l}\text { Share of organic labeled } \\
\text { products }\end{array}$ \\
\hline & & $\begin{array}{l}\text { Share of environmentally friendly } \\
\text { material usage }\end{array}$ & employee satisfaction \\
\hline \multirow{5}{*}{$\begin{array}{l}\text { food transportation } \\
\text { food retail }\end{array}$} & \multirow{6}{*}{ Total output } & & $\begin{array}{l}\text { Share of trained employees on } \\
\text { sustainability } \\
\text { food safety issue }\end{array}$ \\
\hline & & Cost of energy consumption & Share of reliable delivery \\
\hline & & Share of fridges with high grade label & Share of qualified food \\
\hline & & $\begin{array}{l}\text { Share of environmentally friendly } \\
\text { material usage }\end{array}$ & food traceability \\
\hline & & Cost of energy consumption & Employee satisfaction \\
\hline food catering & & Cost of waste disposal & customer complaint \\
\hline
\end{tabular}

Note. All the indicators are measured annually.

\subsection{An Assessment Framework with Fuzzy TOPSIS}

Technique for order preference by similarity to ideal solution (TOPSIS) proposed by Hwang and Yoon (1981) is a widely recognized MCDM technique to assess the performance of alternatives through the similarity with the ideal solution. The concept of TOPSIS is to compute the distance of the evaluated object with the ideal solution and negative-ideal solution simultaneously and further determine ranking order (Li, 2012; Wang, 2005; Wang etc., 2008). The fuzzy TOPSIS approach involves fuzzy assessments of criteria and alternatives in TOPSIS. The steps of fuzzy TOPSIS are as follows:

Step 1: Assign respective ratings to the criteria and food supply chains

Suppose there are $\mathrm{J}$ food supply chains denoted as $A=\left\{A_{1}, A_{2}, \ldots, A_{\mathrm{j}}\right\}$ which are to be assessed with to respect $\mathrm{n}$ criteria, $C=\left\{C_{1}, C_{2}, \ldots, C_{i}\right\}$. The criteria weights are expressed as $w_{i}(i=1,2, \ldots, m)$. The food supply chains performance ratings of each evaluator $D_{k}(k=1,2, \ldots, K)$ for each food supply chain $A_{j}(j=1,2, \ldots, n)$ against criteria $C_{i}(i=1,2, \ldots m)$ are expressed as $\widetilde{R}_{k}=\widetilde{x}_{i j k}(i=1,2, \ldots, m ; j=1,2, \ldots, n ; k=1,2, \ldots, K)$

Step 2: Calculate aggregate fuzzy ratings for the criteria and the food supply chains.

If the fuzzy ratings of evaluators are denoted as triangular fuzzy number $\widetilde{R}_{k}=\left(a_{k}, b_{k}, c_{k}\right), k=1,2, \ldots, K$.

Then the aggregated fuzzy rating can be denoted by $\widetilde{R}=(a, b, c), k=1,2, \ldots, K \quad$ where $a=\min _{k}\left\{a_{k}\right\}, b=\frac{1}{k} \sum_{k=1}^{K} b_{k}, c=\max _{k}\left\{c_{k}\right\}$. 
If the fuzzy rating and weight of the $k$ th evaluator are $\tilde{x}_{i j k}=\left(a_{i j k}, b_{i j k}, c_{i j k}\right)$ and $\widetilde{w}_{i j k}=\left(w_{j k 1}, w_{j k 2}, w_{j k 3}\right), i=1,2, \ldots, m ; j=1,2, \ldots, n$. Then the aggregated fuzzy ratings $\left(\tilde{x}_{i j}\right)$ of food supply chains against each criteria can be denoted as $\tilde{x}_{i j}=\left(a_{i j}, b_{i j}, c_{i j}\right)$, where $a_{i j}=\min _{k}\left\{a_{i j k}\right\}, b_{i j}=\frac{1}{k} \sum_{k=1}^{K} b_{i j k}, c_{i j}=\max _{k}\left\{c_{i j k}\right\}$

The aggregated fuzzy weights $\left(\widetilde{w}_{i j}\right)$ of each criterion are computed as $\widetilde{w}_{j}=\left(w_{j 1}, w_{j 2}, w_{j 3}\right)$ where

$$
w_{j 1}=\min _{k}\left\{w_{j k 1}\right\}, w_{j 2}=\frac{1}{K} \sum_{k=1}^{K} w_{j k 2}, w_{j 3}=\max _{k}\left\{c_{j k 3}\right\}
$$

Step 4: Normalize the fuzzy decision matrix

Linear scale transformation is employed to normalize raw data to make the various criteria scales comparable.

The normalized fuzzy decision matrix $\widetilde{R}=\left[\widetilde{r}_{i j}\right]_{m \times n}, i=1,2, \ldots, m ; j=1,2, \ldots, n$

Where:

$$
\begin{aligned}
& \widetilde{r}_{i j}=\left(\frac{a_{i j}}{c_{j}^{*}}, \frac{b_{i j}}{c_{j}^{*}}, \frac{c_{i j}}{c_{j}^{*}}\right) \text { and } c_{j}^{*}=\max _{i} c_{i j} \text { (benefit criteria) } \\
& \widetilde{r}_{i j}=\left(\frac{a_{j}^{-}}{c_{i j}}, \frac{a_{j}^{-}}{b_{i j}}, \frac{a_{j}^{-}}{a_{i j}}\right) \text { and } a_{j=1}^{-}=\min _{i} a_{i j} \text { (cost criteria) }
\end{aligned}
$$

Step 5: Calculate the weighted normalized matrix

The weighted normalized matrix $\widetilde{V}$ for criteria is computed by multiplying the weights $\widetilde{w}_{j}$ of evaluation criteria with the normalized fuzzy decision matrix $\widetilde{r}_{i j}$.

$$
\widetilde{V}=\left[\widetilde{V}_{\mathrm{ij}}\right]_{\mathrm{m} \times \mathrm{n}}, i=1,2, \ldots, n, \text { where } \widetilde{v}_{i j}=\widetilde{r}_{i j}(\bullet) \widetilde{w}_{j}
$$

Step 6 : Calculate the fuzzy positive ideal solution(FPIS) and fuzzy negative ideal solution(FNIS). They can be computed as follows:

$$
A^{*}=\left(\widetilde{V}_{1}^{*}, V_{2}^{*}, \ldots, \widetilde{V}_{\mathrm{n}}^{*}\right)
$$

Where $\tilde{v}_{j}^{-}=\min \left\{v_{i j 1}\right\}, i=1,2, \ldots, m ; j=1,2, \ldots, n$

Step 7: Calculate the distance of each food supply chain from FPIS and FNIS.

The distance $\left(d_{i}^{*}, d_{i}^{-}\right)$of each weighted supply chain $\mathrm{i}=1,2, \ldots, \mathrm{m}$ from the FPIS and the FNIS is calculated as follows:

$$
d_{i}^{*}=\sum_{j=1}^{n} d_{v}\left(\widetilde{v}_{i j}, \widetilde{v}_{j}^{*}\right), i=1,2, \ldots, m \quad d_{i}^{-}=\sum_{j=1}^{n} d_{v}\left(\widetilde{v}_{i j}, \widetilde{v}_{j}^{-}\right), \quad i=1,2, \ldots, m
$$


Where $d_{v}(\widetilde{a}, \widetilde{b})$ is the distance measurement between two fuzzy numbers $\widetilde{a}$ and $\widetilde{b}$.

Step 8: Calculate the closeness coefficient $\left(C C_{i}\right.$ ) of each food supply chain.

The closeness coefficient $C C_{i}$ represents the distances to the fuzzy positive ideal food supply chain and the fuzzy negative food supply chain.

The closeness coefficient of food supply chains involved is computed as:

$$
C C_{i}=\frac{d_{i}^{-}}{d_{i}^{-}+d_{i}^{*}}, i=1,2, \ldots, m
$$

Step 9: Rank the food supply chains.

Relevant food supply chains are ranked in accordance with the closeness coefficient in decreasing order. The best performing food supply chain is closest to the FPIS and farthest from the FNIS.

\section{Discussion and Conclusion}

Conducting a benchmarking analysis of supply chains is an effective way to improve its sustainable performance. In this study, an original evaluation framework is developed to determine how well food supply chains perform. The developed framework in this article can be utilized by such stakeholders as social experts, consumers, environmental organizations and relevant investors to inform their decisions. Managerially, it can provide Chinese experts in food supply chains with insight into the specific aspects which need to be enhanced so as to enhance sustainability performance. Moreover, potential users of the proposed methodology can set a desirable sustainability indicator target, and compare a specific supply chain with the targeted one so as to measure how well the supply chain is performing in accordance with the set targets and put forward countermeasures to bridge the gap.

Despite the advantages outlined above, there are disadvantages and limitations to be overcome in the future study. The proposed framework did not take all possible factors and indicators into consideration. A more wide and comprehensive range of indicators are to be taken into account in future research. Broader perspective, more in-depth survey and the development of better data acquisition systems in the future may address these disadvantages and limitations.

Sustainability performance assessment is a rich and promising area for academic research that is still in its infancy and has the potential to affect future government policy, current production operations, and identify new business models. The current study sheds light on sustainability performance of food supply chains and offers a strong starting point for follow-up research.

\section{Acknowledgements}

This paper is Supported by The Department of Education in Shannxi, Project number: 19JZ017, "How to achieve sustainable supply chain".

\section{References}

Ahi, P., \& Searcy, C. (2013). A comparative literature analysis of definitions for green and sustainable supply chain management. Journal of Cleaner Production, 52(4), 329-341.

Babu, S., \& Mohan, U. (2018). An integrated approach to evaluating sustainability in supply chains using evolutionary game theory. Computers \& Operations Research, 89, 269-283.

Barrett, H. R. (1999). Globalisation and the changing networks of food supply: the importation of fresh horticultural produce from Kenya into the UK. Transactions of the Institute of British Geographers, 24(2), $159-174$.

Bekele A. (2012). Assessing the sustainability of food retail business: the case of Konsum Varmland, Sweden, Journal of Service Science and Management, 5, 373-385.

Dani, S., \& Deep, A. (2010). Fragile food supply chains: reacting to risks. International Journal of logistics: research and application, 13(5), 395-410.

DEFRA (Department for Environment, Food and Rural Affairs). (2006). Food industry sustainability strategy. London: DEFRA Publication.

Demeke, B. (2018). Green Net Value Added as a sustainability metric based on life cycle assessment: An application to Bounty paper towel, Journal of Cleaner Production, 170, 742-752. 
Den, O., \& Zuurbier, P. J. P. (1996). Vertical cooperation in agricultural Production marketing Chains-with Special Reference to Product Differentiation in Pork. Agribusiness, 12(3), 277-290.

Diabat, A., Govindan, K., \& Panicker, V. V. (2012). Supply chain risk management and its mitigation in a food industry. International Journal of Production Research, 50(11), 3039-3050.

Elkington, J. (1999). Cannibals with Forks, the Triple Bottom Line of the $21^{\text {st }}$ Century Business. Capstone Publishing Ltd, Oxford.

Govindan, K. (2018). Sustainable consumption and production in the food supply chain: A conceptual framework. International Journal of Production Economics, (195), 419-431.

He, B., Luo, T., \& Huang, S. (2019). Product sustainability assessment for product life cycle. Journal of Cleaner Production, 206, 238-250.

Hwang, C. L., \& Yoon, K. (1981). Multiple attribute decision making. Berlin: Springer-Verlag.

Ilbery, B., \& Maye, D. (2005). Food supply chains and sustainability: evidence from specialist food producers in the Scottish English boders. Land Use Policy, 22(4), 331-344.

International Resource Panel. (2010). Priority products and materials: assessing the environmental impacts of consumption and production. United Nations Environment Programme.

Jain, V., Wadhwa, S., Deshmukh, S. G. (2009). Select supplier-related issues in modeling a dynamic supply chain: potential, challenges and direction for future research. International Journal of Production Research, 47(11), 3013-3039.

Li, M. (2012). The application of AHP and TOPSIS in vendor selection and assessment. Logistics Project and Management, 34(8), 67-69.

Lin R. J., Chen, R. H., \& Nguyen, T. H. (2011). Green supply chain management performance in automobile manufacturing industry under uncertainty. Social and Behavioral Sciences, 25, 233-245.

Liu, Y. M. (2011). Studies on the food industry green supply chain management and performance evaluation. Jiangnan University.

Mintcheva, V. (2005). Indicators for environmental policy integration in the food supply chain(the case of the tomato ketchup supply chain and the integrated product policy). Journal of Cleaner Production, 13, 717-731.

Olugu E. U., Wong, K. Y., \& Shaharoun, A. M. (2011). Development of key performance measures for the automobile green supply chain. Resources Construction and Recycling, 55, 567-579.

Pope, J., Annandale, D., \& Morrison-Saunders, A. (2004). Conceptualising sustainability assessment. Environmental Impact Assessment Review, 24, 595-616.

Shannon, C. E. (1948). The mathematical theory of communication, Bell System Technical Journal, 27, $379-423$.

Song, C. (2011). Food supply chain risk management: a sequential game between retailers and regulating government in the face of strategic consumers. State University of New York.

Touboulic, A, Walker, H. (2015). Theories in sustainable supply chain management: a structured literature review. International Journal of Physical Distribution \& Logistics Management, 45(45).

Tsai, W. H., \& Hung, S. J. (2009). A fuzzy goal programming approach for green supply chain optimisation under activity-based costing and performance evaluation with a value-chain structure, International Journal of Production Research, 47(18), 4991-5017.

Wang et al. (2012). A fuzzy Model for Aggregative Food Safety Risk Assessment in Food Supply Chains. Production Planning \& Control, 23(5), 377-395.

Wang X. B. (2005). Supplier appraisal model under short-term of logistics integration. Management Project, $19(2), 1-5$.

Wang, B., Fu, X. Z., Zhang, S. K. (2008). Study on fresh farm supplier based on Entropy and Topsis. An Hui Agriculture Science, 36(13), 5626-5628.

Wang, G. L. (2010). Based on supply chain management of food security early warning. Wuhan University of Technology.

Wang, Z. H., \& Zhan, W. (2012). Dynamic engineering multi-criteria decision making model optimized by entropy weight for evaluating bid. Systems Engineering Procedia, 5, 49-54. 
Wikipedia. (2008). Chinese milk scandal. http://en.wikipedia.org/wiki/2008-Chinese-milk-scandal.

Wu, K. J., Tseng, M. L., \& Vy, T. (2011). Evaluation the drivers of green supply chain management practices in uncertainty, Social and Behavioral Sciences, 25, 384-397.

Yakovleva, N., Sarkis, J., \& Sloan, T. (2012). Sustainable benchmarking of supply chain: the case of the food industry. International Journal of Production Research, 50(5), 1297-1317.

Zhu, Q. H. (2011). Evaluating green supply chain management among Chinese manufacturers from the ecological modernization perspective. Transportation Research, 47, 808-821.

\section{Copyrights}

Copyright for this article is retained by the author(s), with first publication rights granted to the journal.

This is an open-access article distributed under the terms and conditions of the Creative Commons Attribution license (http://creativecommons.org/licenses/by/4.0/). 